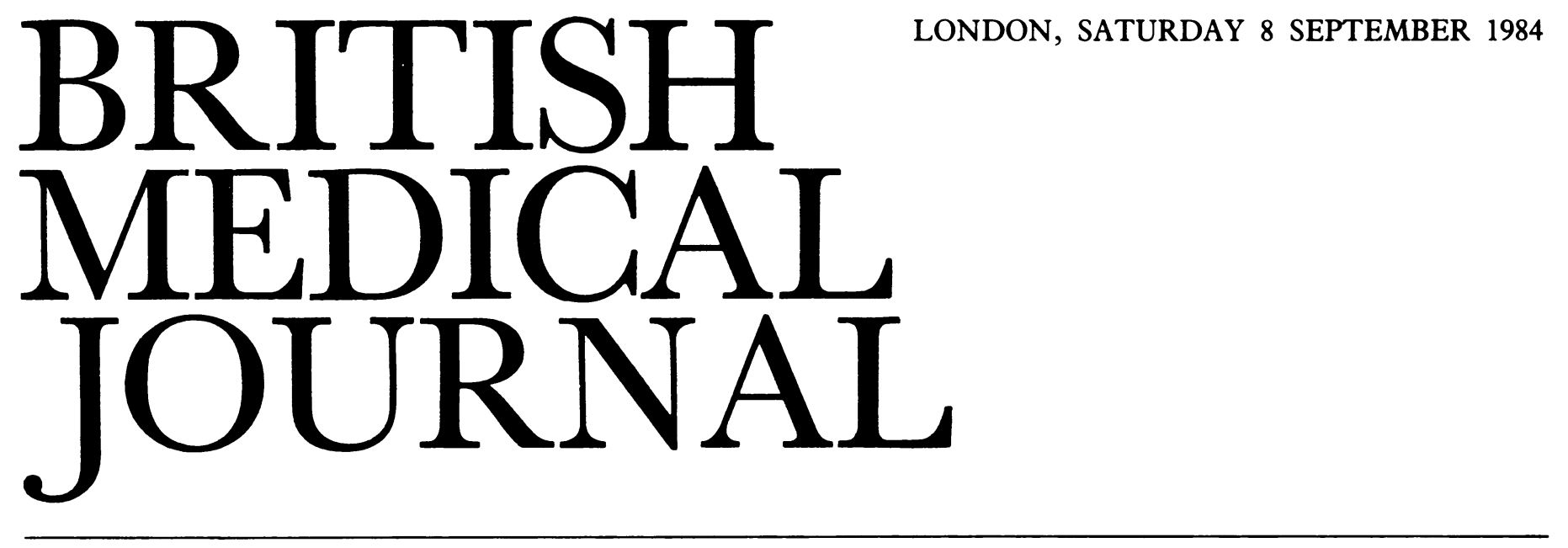

\title{
Computer aided decision making in medicine
}

It is now 30 years since Nash's patent Logoscope was introduced as a mechanical aid to diagnosis ${ }^{1}$ and 25 years since mathematical analysis of rational clinical judgment was established as a possibility. ${ }^{2}$ The aims and principles of computer assisted decision making were laid down by Lee Lusted and Wilfrid Card in the $1960 \mathrm{~s},{ }^{34}$ and over 1000 papers have now been published on this subject, with their scope ranging from single problems such as alcoholism ${ }^{5}$ and allergy ${ }^{6}$ to an ambitious attempt to tackle $75 \%$ of internal medicine in a unified program. ${ }^{7}$ Yet, though computers are established in signal processing, data analysis, and physiological modelling and are slowly coming into record systems, they have been used routinely only rarely for explicit help in medical decisions. Recent articles, however, argue that a critical time has arrived. ${ }^{89}$

Four types of programs should be distinguished: algorithmic, automatic interpretation, actuarial, and advice systems. The first of these are simply transpositions to a computer of flow charts for good clinical practice, such as those recently appearing in the $B M \mathcal{F}$ or those for rural health workers in developing countries. ${ }^{10}$ The main use of such computer algorithms is in home medical programs such as The Complete Guide to Medicine (for only 16.90), though in the United States they have been adopted for complex protocols for cancer treatment. ${ }^{11}$

The second type of program performs an automatic interpretation of clinical measurements already collected on a computer, such as the recent suggestion for on line detection of rejection of renal transplants. ${ }^{12}$ Considerable experience has been gained in automatic interpretation of electrocardiograms, and commercial systems have recently become cheaper and more widespread. ${ }^{13}$ The problems of reliable analysis have so far, however, prevented extensive applications in monitoring intensive care,${ }^{14}$ though automatic control of infusion of drugs has been reported. ${ }^{15} 16$ The advantage of this type of system is that it avoids any additional burden on staff and may be attached to standard apparatus, such as the computer interpretation of lung function tests routinely used in at least one clinic. ${ }^{17}$

The third, actuarial, type of system provides a measure of the risk of some future event, given certain precisely defined

(C) BRITISH MEDICAL JOURNAL 1984. All reproduction rights reserved. information concerning the present state of the patient. The aim is to extract the maximum evidence from "cheap" information so that initial judgments may be reinforced to the point where an early decision is made and the delay and expense of further observation or investigations are avoided. The underlying philosophy is identical with that of a risk factor analysis such as assessing the chance of haematoma after head injury, ${ }^{18}$ but in complex problems with many possible outcomes and items of information statistical modelling and a computer become necessary. The most prominent work on such topics has been by de Dombal's group in Leeds, whose system for assessing the chances of different causes of acute abdominal pain is now being evaluated in a controlled trial in eight casualty departments in England as well as having been used in other hospitals and in United States Navy submarines for some years. ${ }^{19}$ Systems for other diseases have been developed by his group and tested in extensive international collaboration..$^{20}$ From Glasgow has come a dyspepsia program that obtains data on symptoms by direct interviewing of the patient by computer $^{2122}$; the interview has been translated into Swedish and Dutch, and the diagnosis system is being tested in clinics in Britain and overseas. An allergy program is also being tested in a number of centres, ${ }^{6}$ and in the United States a predictive program on a hand held calculator has recently been shown to reduce unnecessary admissions to coronary care units in six hospitals. ${ }^{23}$ In each of these systems the emphasis is on establishing the appropriate questions and eliciting the response correctly; except when used in interviewing patients the computer is almost incidental, and, as de Dombal has emphasised, the whole process can be considered to be "just another test.",

In contrast with this deliberately restricted role, advice programs are intended to act in the manner of an interactive consultation, and many are being developed under the general term "expert systems." ${ }^{24}$ Explicitly modelling medical knowledge using techniques in artificial intelligence is an exciting exercise, though (despite press reports) such programs have not been applied outside their place of development. Basic prompting systems have been introduced into clinics, ${ }^{25}$ but there are clearly problems in getting a busy 
decision maker to have an extended dialogue with a computer.

Many explanations have been put forward for the apparently meagre use made of computers in decision making: some have blamed the poor interface, reliability, and design of systems, the lack of proved benefit, and the disruption to routine that can come about through thoughtless implementation $^{26}$; such problems may also occur with computerised record systems..$^{27} \mathrm{~A}$ recent commentator has also blamed the pride and inertia of doctors and the teaching in medical schools. ${ }^{28}$ Proponents of an artificial intelligence perspective sometimes claim that actuarial systems are inherently unacceptable as they do not follow accepted clinical reasoning processes. ${ }^{24}$ To a non-clinician, it appears that the astonishing variety of clinical practice must also act against any innovation that tends to impose a degree of standardisation in clinical terms and procedures.

Clearly technological advances are revolutionising attitudes to computers, while greater awareness of costs, both monetary and in patient morbidity, is bringing clinical decision making under increasing scrutiny. Interest in the components of computer assisted decision making now appears to have caught up with established analytic techniques: between 1973 and 1983 the Index Medicus showed that the number of articles under "computers" rose from 370 to 850 , those under "decision making" rose from 64 to 129, while those under "diagnosis: computer assisted" fell from 98 to 65 . As microcomputers become familiar in routine practice we may expect many more applications of automatic interpretation of information-but, as is appropriate for any new technology, the medical profession would be right to be sceptical until benefit has been proved in rigorous evaluations. When that happens computer aids may well come to be seen as basic tools in the art of clinical medicine.

\section{DAvid J SPIEgelHalter}

Statistician

MRC Biostatistics Unit, Medical Research Council Centre,

Cambridge CB2 2QH

Nash FA. Differential diagnosis: an apparatus to assist the logical faculties. Lancet 1954; i:874-6. Ledley RS, Lusted LB. Reasoning foundations of medical diagnosis. Science 1959;130:9-21 Lusted LB. Introduction to medical deciston-making. Springfield, Illinois: C C Thomas, 1968. Card WI. Towards a calculus of medicine. Medical Annual 1967;9:9-21

Lyons JP, Izadi BM. Computer-aided diagnosis of alcoholism. I Stud Alcohol 1980;41:448-55 antin CFA, Merrett TG. Allergy screening using a microcomputer. Br Med f 1982;285:483-7. Miller RA. Pople HE Jr, Myers JD. INTERNIST-1, an experimental computer-based diagnostic consultant for general internal medicine. $N$ Engl 7 . Med 1982;307:468-76.

- Ziporyn T. Computer-assisted medical decision-making: interest growing. FAMA 1982;248:913-8. Dombal FT. Clinical decision making and the computer: consultant, expert, or just anothe

10 Essex BJ. Diagnostic pathways in clinical medicine. 2nd ed. London: Churchill Livingstone, 1980. adjuvant therapy. Ann Intern Med 1979:90:496-501.

adjuvant therapy. Ann Intern Med 1979;90:496-501.
Trimble IMG, West M, Smith AFM, Knapp MS, Pownall R. Computer diagnosis of allograft rejection. Br Med F 1983;286:1695-9.

${ }^{3}$ MacFarlane PW, Peden J, Lennox G, Watts MP, Lawrie TDV. Glasgow system. In: van Bemmel $\mathrm{H}$, Williams J, eds. Trends in computer processed electrocardiograms. Amsterdam: North Holland, 1977:143-50.

4 Asbury AJ, Lush K, Franks CI. ABC of computing: computers in high dependency units. Br Med I 1983;287:472-5.

Price DJ, Dugdale RE, Mason J. The control of ICP using three asynchronous closed loops. In

Shulman K, ed. Intracranial pressure IV. Heidelberg: Springer-Verlag, 1980:395-9.
Jelliffe RW. Computer-controlled administration of cardiovascular drugs. Prog Cardiovasc Dis 1983;26:1-14

Geddes DM, Green M, Emerson PA. Comparison of reports on lung function tests made by chest

, Jennett B, Bryden J, Hessett C, Murray G. Risks of intracranial haematoma in head injured adults. Br.Med F 1983;287:1173-6

de surgeon. A matter of decision. In: Nvhus LM, ed Surgen annual. New York: Appleton-Century-Crofts, 1979:33-57. Organisation of Gastro-Enterology. Scand $\mathcal{F}$ Gastroenterol 1984;19(suppl 95):1-58.

${ }^{1}$ Lucas RW, Card WI, Knill-Jones RP, Watkinson G, Crean GP. Computer interrogation of patients. BrMed f 1976;ii:623-5.

2 Spiegelhalter DJ, Knill-Jones RP. Statistical and knowledge-based approaches to clinical decisionsupport systems, with an application to gastroenterology (with discussion). Fournal of the Roval Statistical Sociery $A$ 1984;147:35-77.

3 Pozen MW, D'Agostino RB, Selker HP, Sytkowski PA, Hood WB. A predictive instrument to improve coronary-care-unit admission practices in acute ischemic heart disease. A prospective multicentre clinical trial. $N$ Engl f Med 1984;310:1273-8.

24 Fox J, Alvey P. Computer assisted medical decision-making. Br Med f 1983;287:742-6.

Young DW. An aid to reducing unnecessary investigations. Br Med f 1980;281:1610-1.

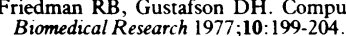

199-201.
${ }^{28}$ Levinson D. Information, computers and clinical practice. FAMA 1983;249:607-9.

\section{Falls in older age}

One of the common questions that has to be answered by physicians responsible for old people is: did the patient trip, slip, or just fall down? Indeed, so many body systems are concerned in the maintenance of posture that experienced physicians are not surprised when the multiple disorders accompanying aging produce not one but several weak links in the control of balance, precipitating a fall.

One of the additional contributing factors is the effect of age on the control of body "sway." This phenomenon was recognised by Sheldon ${ }^{1}$ and has since been confirmed by Overstall and colleagues. ${ }^{2}$ Though falls are common in the old they do not occur all the time, and acute disturbances may be required to aggravate the effects of sway. For an active elderly person such an event may be associated with minimal disease, may be described as an accident, and is likely to occur in the home (one third happen on the stairs) as Sheldon showed in his pioneering work almost 25 years ago. ${ }^{3}$

Medicolegal responsibilities make it all the more important to determine the factors associated with falls in institutions. In a recent investigation, underlying the grave problems faced in social service (part III) homes for the elderly, $59 \%$ of 201 residents were found by Woodhouse and colleagues to have had one or more falls in a year; $22 \%$ of these had resulted in some form of injury. ${ }^{4}$ The purpose of this survey was to determine the prevalence and rate of falling in residents of these homes and to define the characteristics of those who fell. It did not set out to determine causes. Comparison with other surveys is difficult because (as the authors point out) both the methods of ascertainment of falls and the general level of disability of the groups that have been studied are variable. Further studies on falls should be population based, as has been suggested by Perry.

Until these results are available, what advice can be offered to busy general practitioners about the methods that might be used to reduce the risk of morbidity from falls in individuals and the investigations that should be carried out in those not seriously injured? The need-still widely unrecognised - for health care of the elderly at home is more important now than when it was described 20 years ago, but the amount of work required need not be excessive if simple primary preventive care is placed in the hands of an interested and informed practice nurse or health visitor. ${ }^{6}$ Screening to discover and treat diseases of eyes, ears, and feet should be accompanied by advice on avoiding home accidents.

Secondary prevention may require the equally simple measure of kind reassurance to restore confidence after a fall; sometimes a more clinical evaluation is warranted. An unexplained fall in old age may be associated with a fracture of the femur' or be the presenting feature of any acute illness. If there is no obvious or serious injury the practitioner should determine whether the event was due to an accident, an incident, or an illness. Accidents may be due to preventable hazards including visual deterioration and drug effects. Incidents are common in institutions during changes in posture or position, notably while using the toilet or transferring between bed and chair, and may be the early sign of an inevitably increasing dependency from unavoidable physical and mental decline. Unexpected falls, however, require further investigation. Obvious acute illness indicates its own treatment, but in other cases 